\title{
30
}

\section{Taphonomic analysis of the Twilight Beach seals}

\author{
Lisa Nagaoka \\ Department of Geography, University of North Texas, USA \\ Inagaoka@unt.edu \\ Steve Wolverton \\ Department of Geography, University of North Texas, USA

\section{Ben Fullerton} \\ Department of Geography, University of North Texas, USA
}

\section{Introduction}

Taphonomic studies have become an integral part of zooarchaeological research over the past 30 years. Understanding the processes that led to the samples of animal remains found in archaeological sites is crucial for evaluating the validity of interpretations of these datasets (Klein and Cruz-Uribe 1984; Lyman 1994a). It is important to recognise that taphonomic analysis, 'as the science of the laws of embedding or burial' (Lyman 1994a:1), is not done for its own sake, but to solve problems in zooarchaeological research (e.g. Gifford-Gonzalez 1991; Lyman 1994a; Stiner 2005). The purpose of this paper is to highlight the importance of taphonomic analyses, and provide an example of a detailed taphonomic analysis of a fauna - the Twilight Beach fauna - related to particular research questions in New Zealand.

One of the earliest taphonomic studies in New Zealand was Michael Taylor's (1982) work on the Twilight Beach fauna. Since then, taphonomic and zooarchaeological methodology has changed considerably. For example, detailed syntheses of quantitative methods in zooarchaeology have been published (Grayson 1984; Lyman 1994b, 2008). As important experimental studies of carnivore ravaging of bone assemblages have been undertaken (Marean and Spencer 1991; Marean et al. 1992), density-related preservation and destruction of bone has been studied extensively (Lyman 1994a; Lam et al. 2003; see also Darwent and Lyman 2002), the effects of differential recovery of remains on zooarchaeological analyses are better understood (Shaffer 1992; Gordon 1993; Shaffer and Sanchez 1994; Nagaoka 1994, 2005a), and fragmentation 
has been explored as a proxy of several taphonomic processes, including the use of withinbone nutrients (marrow and grease) by humans (Marean and Kim 1998; Wolverton 2002; Munro and Bar-Oz 2005; Nagaoka 2005b, 2006). In addition, comprehensive syntheses on taphonomy have been published (e.g. Lyman 1994a; Fisher 1995). Finally, extensive analyses that incorporate taphonomy in subsistence zooarchaeology are becoming more commonplace (e.g. Broughton 1999; Munro 2004; Stiner 1994, 2005).

Taphonomic analyses are somewhat under-utilised in Pacific Island archaeology, and there is ample room for expanding their depth and breadth in New Zealand. The most important goal of taphonomic analysis is to evaluate the suitability of faunal samples for answering particular research questions. Taphonomic analysis helps answer the question: 'Are we studying what we think we are studying?' We use our re-analysis of the Twilight Beach seal assemblage to illustrate how this question can be addressed. Although a taphonomic study of the Twilight Beach sample was done previously (Taylor 1982), the research was primarily descriptive and methodological and did not focus on particular archaeological or ecological research questions.

Taphonomic analysis in practice often lacks a theoretical perspective (but see Lyman 1994a), and our opinion is that failure to use conceptual guide posts has produced variability in what it means to assess a zooarchaeological assemblage taphonomically (compare Marean and Kim 1998 and Pickering et al. 2003 to Stiner 2002). George Gaylord Simpson's (1963) distinction between immanent and configurational properties of phenomena in the historical sciences is deeply relevant to studies that incorporate taphonomic analysis (Lyman 1994a). The two concepts, immanence and configuration, provide structure and direct goals for taphonomy in zooarchaeology. Simpson (1963:24-25) defines the two properties in the following manner:

The unchanging properties of matter and energy [for example, those of chemistry, physics, and mechanics] and the likewise unchanging processes and principles arising therefrom are immanent in the material universe. They are nonhistorical, even though they occur and act in the course of history. The actual state of the universe or of any part of it at a given time, its configuration, is not immanent and is constantly changing. It is contingent ... or configurational ... History may be defined as configurational change through time.

Immanent properties are those that are the same in all places and times, and for which we can derive 'law-like' statements. For example, the taphonomic effect of bone struck with a certain amount of force in a particular direction will be the same whether the taphonomic agent is a bison trampling the bone, or a human flaking the bone, or a river rock striking the bone during saltation. The physics of flaking bones (or stones) is unchanging across time and space. On the other hand, configurational properties are contingent on historical circumstances. In other words, they are unique to a particular situation. For example, each faunal assemblage will have its own taphonomic history that is configurational (unique because of the specific circumstances in which the assemblage was created, preserved and recovered). Often in taphonomic studies we record the magnitude or severity with which immanent properties occur in order to document configurational properties. For example, burning is an immanent property because it produces a specific pattern on bone that is different from other taphonomic processes. When we record the degree of burning on bone, we are examining the configurational properties of burning for a bone or an assemblage. We are unable to derive laws about what temperature the different categories of burning represent, except in only the broadest sense (e.g. calcined bone; Lyman 1994a:386).

This distinction between immanent and configurational properties is important because only immanent properties hold to the uniformitarian principles we tout as the basis for tapho- 
nomy. When we confuse configurational properties for immanent ones, we are saying that the magnitude and pattern of taphonomic damage on bone caused by a particular taphonomic agent should be the same across time and space, which clearly is not the case, despite statements to the contrary (e.g. Marean and Cleghorn 2003 in reference to laws of carnivore damage). In addition, it is important to recognise that studying taphonomic configurational properties provides us with the taphonomic history of an assemblage, which is crucial for evaluating the ability of faunal data to address particular research questions. That configurational history of change (or lack thereof) will include spatio-temporal contingencies in which destructive or preservational processes occurred.

In this study, we provide documentation of the taphonomic configuration of the Twilight Beach fur-seal faunal assemblage to determine whether or not the fauna can be used to adequately address questions related to prehistoric exploitation and prehistoric biogeographic distribution of seals.

This study is designed to examine destructive agents, such as carnivore damage, butchery, weathering, and other processes that influence survival of skeletal parts, and how they affect data used to address larger-scale research questions regarding exploitation of seal carcasses and demographic patterns of seals exploited. For example, recent studies of carcass exploitation highlight that density-mediated attrition, element fragmentation and diagenetic processes can radically alter assemblages (Lyman 1994a; Stiner et al. 1995, 2005). Thus, it is necessary to evaluate the taphonomic history of the assemblage and how it has impacted skeletal element representation and bone fragmentation, both of which are variables used to understand carcass exploitation. In addition, the demographic data gathered from the seal remains will be used to determine whether seals were being exploited from haul outs and/or rookeries in the far northern reaches of New Zealand. The taphonomic analysis is important here because it can determine whether or not low-density, easily destroyed pup remains are under-represented by evaluating the destructive formation processes (see Schiffer 1987; see also Wolverton 2001, 2006) important in the fauna accumulation history at the site. Understanding the demographic profile represented in the assemblage can help inform seal conservation efforts that use past breeding distributions to model future trends (e.g. Bradshaw et al. 2000, 2002).

\section{Twilight Beach}

The Twilight Beach site is located on the northwestern tip of the North Island of New Zealand (Figure 1). This peninsula of land is flanked by the Pacific Ocean to the east and the Tasman Sea to the west. The region is composed of a sequence of sand dunes that have formed within the past 50,000 years (Taylor 1982). Before human occupation, these sand dunes were covered by light vegetation, which acted to stabilise the sediment and minimise erosion. According to wood, pollen and charcoal data, the region was covered by mixed podocarp-broadleaf forest and scrub before and during initial occupation at Twilight Beach (Taylor 1982). The site was occupied during the early period of human colonisation at about 1005 BP (NZ6579 in Coster 1989:56).

After deposition and burial of the Twilight Beach site, the far north region of New Zealand was stripped bare of vegetation as a result of widespread burning by early Polynesian settlers. The effect of this widespread burning and the associated decrease in vegetation was to expose the sand dunes to long-term wind erosion, which continued

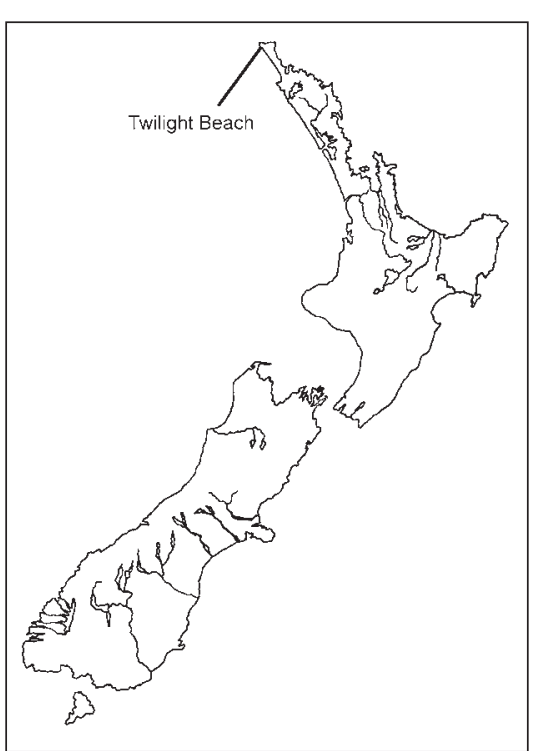

Figure 1. The location of the Twilight Beach site (N1+2/976). 
until the site was excavated. This wind erosion resulted in the exposure and movement of parts of the Twilight Beach deposits, which covered an area of $6 \mathrm{~m}$ by $1.5 \mathrm{~m}$, with a depth of more than $1 \mathrm{~m}$. The southeastern slope was littered with eroded shell debris and some of the deposits were observed falling down the steep northern slope when the site was discovered. Atop the pinnacle of the sand dune was the consolidated portion of the shell midden that could be observed only from the eastern slope.

When it was recognised that the site would be destroyed by ongoing erosion, it was decided it should be investigated (Taylor 1982). The remaining intact deposits were removed in $25 \mathrm{~cm}$ by $25 \mathrm{~cm}$ by $5 \mathrm{~cm}$ slices and about 80 percent of the eroded midden debris covering the surface of the southeastern slope was collected. All matrix recovered was returned to the University of Auckland, where it was screened through nested sieves of $4 \mathrm{~mm}, 2 \mathrm{~mm}$ and $0.5 \mathrm{~mm}$.

The stratigraphy of the site is characterised by five main layers. Level 5 , at the base of the deposits, is a weathered Pleistocene sand layer devoid of cultural materials. This layer was not included in the excavated portions. Above this was a yellow dune-sand layer about $1 \mathrm{~m}$ thick that included some charcoal and shell bioturbated from preceding layers. This layer contained a nearly complete moa skeleton, but the skeleton was not fully excavated. Layer 3 formed the bulk of the deposit and it varied in composition across the site. At the northern end of the site, Layer 3 was characterised by charcoal-stained sediment with sparse cultural deposits. At the southern end, Layer 3 was characterised by a dense matrix of shell, bone and other artefacts. Layer 2 was composed of compact yellow-grey sand and contained very few cultural remains. Finally, Layer 1 , at the top of the site, was composed of a thin, black topsoil with sparse vegetation.

The site produced a large assemblage of animal remains, including remains of shellfish, fish, birds, dogs, seals and cetaceans. Taylor (1982) examined all taxa except the bird sample, which has never been fully analysed. The assemblage has been important in many other faunal studies. The dog remains were used as part of Clark's (1995, 1997a, 1997b) comprehensive morphometric analysis of kuri in New Zealand. The assemblage was also used as part of larger studies examining fish exploitation in the region (Nichol 1988; Leach et al. 1997), which documented a dominance of snapper (Pagrus auratus). Taylor's analysis concentrated mainly on the mammal assemblage, particularly on the seals. Like Taylor's work, our analysis focused on the Twilight Beach fur-seal assemblage. We chose to emphasise fur seals because our larger research questions deal with fur-seal exploitation and because fur seals are the most abundant mammalian taxon, with 2880 identified specimens (NISP), and an MNI of 67 (Taylor (1982). Thus, the fur-seal assemblage is ideal for examining how taphonomic processes can affect faunal data sets.

\section{Taphonomic analysis}

The Twilight Beach seal assemblage was examined for taphonomic factors that could be relevant to carcass exploitation and mortality analysis. Specifically, we examined differential fragmentation, fragmentation patterns, carnivore damage, weathering, burning and cut marks. These taphonomic factors were documented across skeletal elements and body parts (in the manner of Stiner 1994, 2002) to determine whether particular skeletal parts were differentially affected, and if so, why.

\section{Differential attrition of skeletal parts}

While researchers have long recognised that bone mineral density is likely to be an important factor in skeletal element representation (Guthrie 1967; Brain 1969), Lyman (1984) was the first to evaluate this assumption quantitatively. He used photon-densitometry to estimate bone 


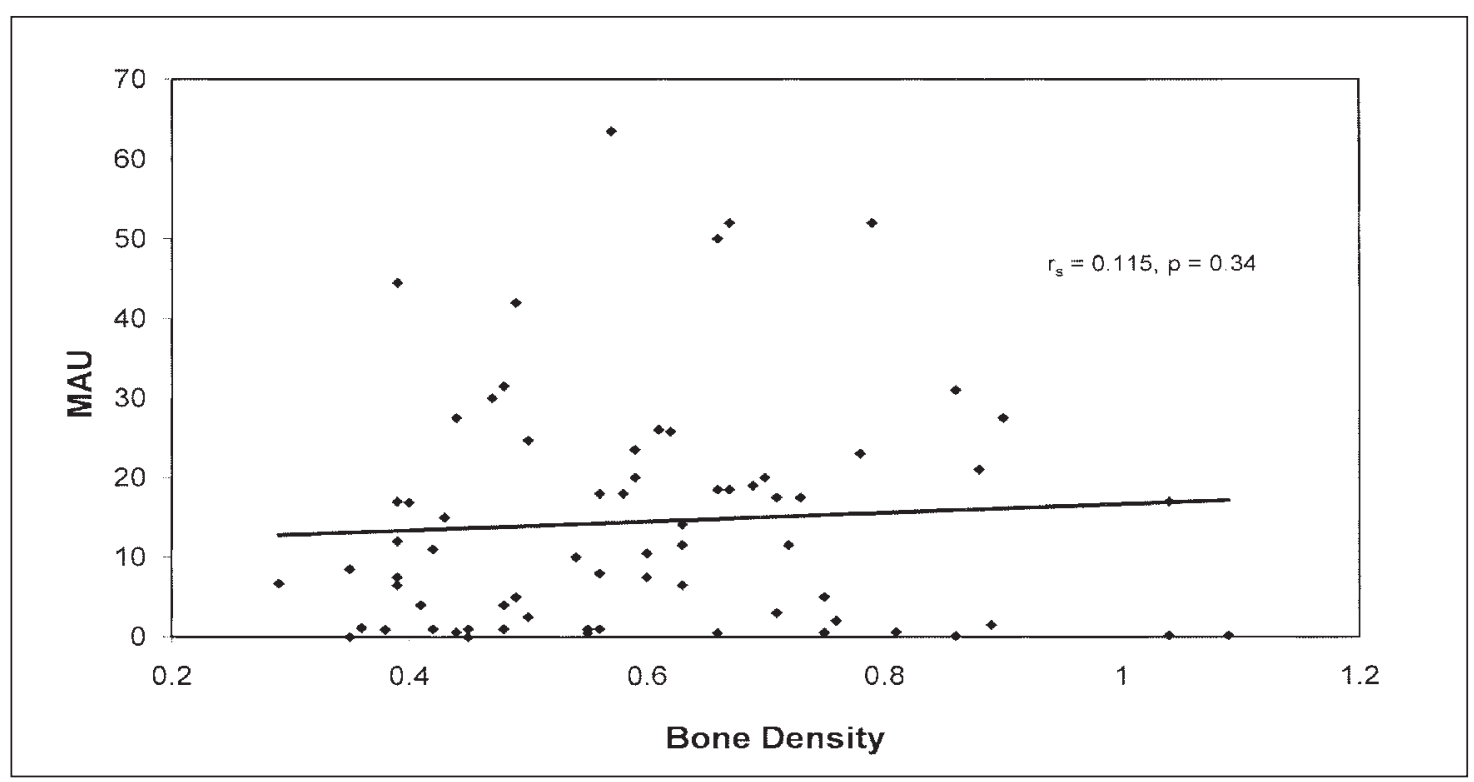

Figure 2. Correlation analysis between bone mineral density and skeletal element representation (MAU) across individual scan sites for Twilight Beach fur-seal remains. The line provides a visual representation of the relationship.

density for several points or scan sites across each skeletal element. Since then, bone-density values for several different vertebrate taxa have been generated (Chambers 1992; Kreutzer 1992; Lyman et al. 1992; Butler and Chatters 1994; Hindelang and Ann 1997; Lam et al. 1999; Pavao and Stahl 1999; Stahl 1999; Dirrigl 2001; Pickering and Carlson 2002; Cruz and Elkins 2003; Ioannidou 2003; Izeta 2005; Novecosky and Popkin 2005), using different techniques (Lam et al. 1998, 2003; Symmons 2004). It has become common practice to assess whether differential attrition of skeletal parts has played a role in the formation of the faunal assemblage.

To determine whether elemental representation of the Twilight Beach fur-seal assemblage has been affected by differential attrition, minimal animal unit (MAU, Binford 1984) by scan site was compared with bone density per scan site (Lyman 1994a). The analysis shows there is no significant correlation nor visual relationship between fur-seal skeletal-element representation at Twilight Beach and seal bone density (Figure 2). Therefore, the assemblage as a whole does not appear to be affected by density-mediated attrition. In other words, overall, denser portions of skeletal elements are not significantly over-represented and less dense portions are not significantly under-represented.

\section{Fragmentation analysis methods}

Analysis of skeletal-element fragmentation has become important for determining how elements have been modified through either cultural or natural processes. In general, the more fragmented an assemblage, the more likely that one or more taphonomic processes have been at work on the elements in the assemblage. While there are numerous ways to measure fragmentation (Marean and Spencer 1991; Lyman 1994a), it is important to make the distinction between measuring the extent and the intensity of fragmentation (Lyman 1994a, 1994c; Wolverton 2002). Extent of fragmentation refers to the proportion of broken elements in an assemblage. Fragmentation extent is often determined using the percentage of whole elements (\% whole) (Todd and Rapson 1988; Lyman 1994b; Wolverton 2002). An assemblage with very few whole elements has a greater extent of fragmentation than one comprised mainly of complete elements. Fragmentation intensity, on the other hand, examines the degree to which an element is fragmented. Several different measures have been used to document intensity of fragmentation. Since an element 
that is more fragmented has a greater number of fragments and those fragments are smaller, measures of intensity have examined both fragment numbers and fragment size (e.g. Marean and Spencer 1991; Lyman 1994b; Wolverton 2002; Outram 2004; Stiner et al. 2005; Nagaoka 2006).

For this study, we used several measures of fragmentation intensity, including the ratio of NISP to MNE (NISP:MNE), the average percent of total scan sites represented per specimen (shortened to 'average percent scan site'), and the average fragment size. NISP:MNE is a measure commonly used to indicate fragment number (Lyman 1994a, c). It takes the total number of specimens identified to a particular element (NISP) and divides that value by the minimum number of elements calculated, based on the most common portion of the element represented. NISP:MNE answers the question: 'Of the elements (MNE) represented in an assemblage, how many specimens (NISP) occur?' In this analysis, we recorded portions of elements by documenting the bone density scan sites represented (Chambers 1992, Lyman 1994a). The value for the most common scan site is the MNE.

Another measure of fragmentation records the zones or portions of an element represented by a specimen (Todd and Rapson 1988), to estimate fragment size. For this assemblage, we used the average percent scan site. For each specimen, the bone density scan sites represented are recorded. The number of scan sites recorded is then divided by the total possible number of scan sites for that element. For example, the humerus has five scan sites. If a humerus specimen has two of the five scan sites present, then that specimen represents 40 percent of that element. The values for all humerus specimens are then averaged to get the average percent scan site for that element in an assemblage.

One limitation of this measure is that the minimum fragment size is determined by the number of scan sites. That is, scan-site coverage is relative to particular elements, and the more scan sites an element has, the smaller a fragment can be. For humeri, the minimum fragment size is 20 percent, since there are five scan sites for this element. If the number of scan sites for an element is three, the minimum size is 33.3 percent; if it is 10 , the minimum size is 10 percent. Thus, the lower threshold of this measure varies across skeletal elements. As a result, the measure may not be appropriate for highly fragmented assemblages. On the other hand, this problem may be mitigated by the fact that as fragment size decreases, there is a corresponding decline in identifiability (Marshall and Pilgram 1991; Lyman 1994a; Wolverton 2002). If the minimum identifiable size range corresponds to the minimum scan site percentage, this may not be a problem. Further, average percent scan site can be scaled across elements such that the lowest common scan-site coverage is used, and if data are treated at ordinal scale, fragmentation can then be described as low, medium or high intensity.

Our final measure of fragmentation is an absolute measure. Each specimen was measured with a digital caliper to the nearest $0.01 \mathrm{~mm}$ to obtain the length of the maximum dimension of each fragment (as in Stiner et al. 2005). For this assemblage, we measured the maximum fragment length for just a few elements (humerus, radius, ulna, femur) as an experiment, to evaluate the utility of this method for New Zealand seal assemblages. The measurements of fragmented specimens for each skeletal element were then averaged.

\section{Fragmentation analysis results}

For the Twilight Beach seal assemblage, the extent of fragmentation is high. Only 1.3 percent of the seal remains are complete (Table 1). For most elements, none of the specimens are complete (Figure 3). There are no whole crania, vertebrae, scapulae, radii, innominates, nor tibiae. Fragmentation is least extensive for the lower limb bones. About 30 percent of metapodials 
Table 1. Occurrence of taphonomic processes on the Twilight Beach seal assemblage.

\begin{tabular}{ll}
\hline Taphonomic process & Assemblage total \\
\hline Extent of fragmentation (\% Whole) & 1.3 \\
Intensity of fragmentation (NISP:MNE) & 2.9 \\
Weathering (\% NISP) & 13.6 \\
Carnivore damage (\% NISP) & 9.0 \\
Rodent gnawing (\% NISP) & 0.3 \\
Cut marks (\% NISP) & 3.2 \\
Burning (\% NISP) & 4.2 \\
\hline
\end{tabular}

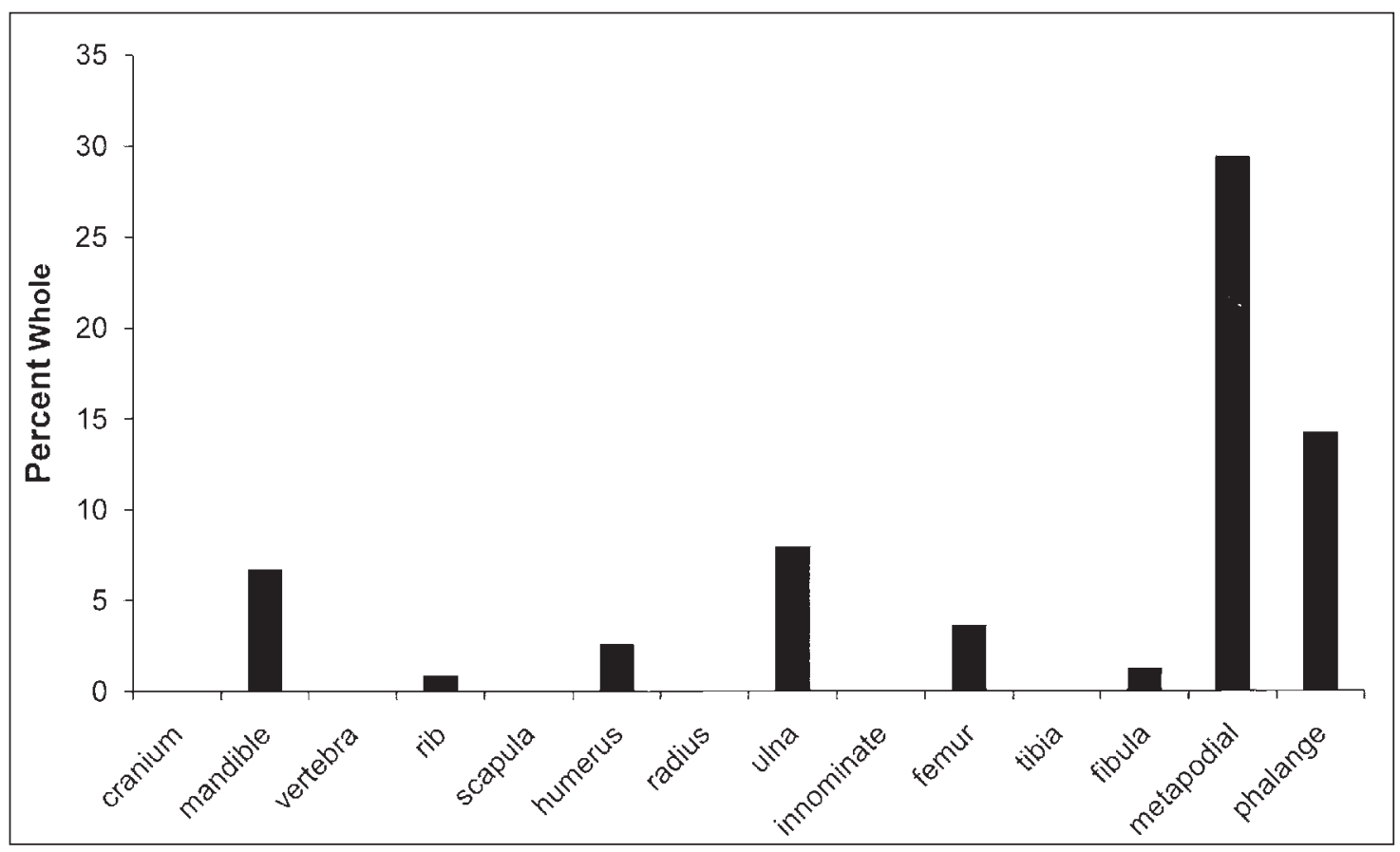

Figure 3. Percentage of whole elements.

and 15 percent of phalanges are complete. Often the percentage of whole long bones is low in studies that focus on terrestrial mammals because these elements are fractured for marrow extraction (Munro and Bar-Oz 2005). However, seals do not have large marrow cavities in their long bones, like terrestrial mammals. The paucity of whole long bones at Twilight Beach more likely reflects the predominance of unfused juvenile specimens. Very few of the ends of longbone elements that are present are fused. Further, those elements that exhibit a relatively high percentage of whole bones tend to be from flippers (metapodial phalanges), the structure of which may have offered some protection from fragmentation processes (e.g. human fracturing for within-bone nutrients).

Although most specimens are fragmented (low \%whole), the intensity of fragmentation is relatively low for all measures. For NISP:MNE, the fragmentation rate across elements is about two fragments or fewer per element (Figure 4). Most elements have an average percent scan site that falls between 30 percent and 60 percent (Table 2, Figure 5), supporting the NISP:MNE results and the interpretation that elements are fragmented into only two or three pieces. In fact, 

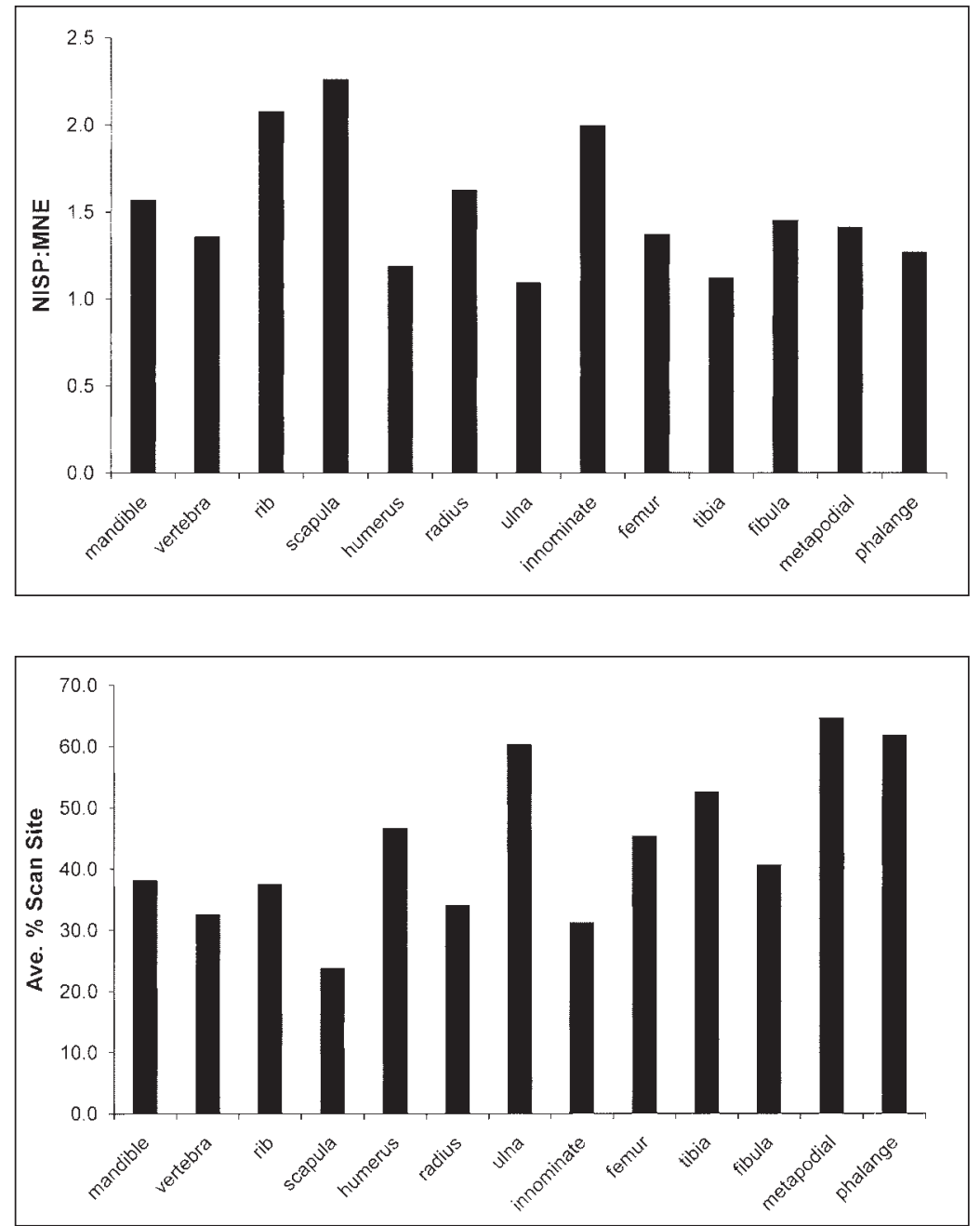

Figure 4. Ratio of specimen fragments (NISP) to the minimum number of elements (MNE).

Figure 5. Average percent scan site across elements.

Table 2. Number of scan sites and the average percent scan site for each element.

\begin{tabular}{lll}
\hline Element & Nunber of scan sites & Average \% scan site \\
\hline Mandible & 6 & 38.2 \\
Vertebrae & 3 & 32.7 \\
Rib & 5 & 29.3 \\
Scapula & 8 & 23.9 \\
Humerus & 5 & 46.8 \\
Radius & 5 & 34.2 \\
Ulna & 4 & 60.4 \\
Innominate & 7 & 31.3 \\
Femur & 6 & 45.5 \\
Tibia & 5 & 52.6 \\
Fibula & 5 & 40.8 \\
Metapodial & 3 & 64.7 \\
Phalange & 3 & 61.9 \\
\hline
\end{tabular}


when the two measures are compared with one another, there is a negative correlation (Figure 6, $\mathrm{rs}=-0.89, \mathrm{p}<0.001)$. As expected, the larger the fragment, as represented by increasing average percent scan site values, the fewer the fragments, as seen in the lower NISP:MNE values.

Average scan site data can be directly compared with NISP:MNE by calculating the expected number of fragments, based on the scan sites represented. For example, the humerus has five scan sites; dividing 100 percent by the average percent scan site of 46.8 percent gives an expected number of fragments per humerus (expected NISP:MNE) of 2.14. This can be compared with the actual NISP:MNE per element from the assemblage to determine how well average percent scan site measures fragmentation intensity. When the actual NISP:MNE values are compared with the values derived from the scan-site information, the scan-site data consistently overestimate fragmentation relative to NISP:MNE (Figure 7). It is likely the overestimation of fragment size is because the average scan site is constrained by the number of scan sites, as discussed earlier. A more detailed evaluation will require analysis of fragment size metrically on fragments of specimens from same-age/sex individuals, which we are unable to do using the Twilight Beach fauna. What is important here is that NISP:MNE and average percent scan site positively correlate, indicating that both measure fragmentation size/intensity at ordinal scale.

Fragment size for humeri, ulnae, radii and femora specimens were measured in their longest dimension to the nearest $0.01 \mathrm{~mm}$ to provide another reference point for the intensity of fragmentation (Lyman and O'Brien 1987; Outram 2001). Figure 8 shows the frequency distribution of the size data across elements. The graphs for the humeri, ulnae, radii and femora show a unimodal distribution of fragment size, indicating that in this assemblage, most long-bone fragments are medium in size, with some small and a few large. In general, few large fragments can indicate that \%whole is low; however, few small fragments reflects either that there truly is a low representation of small fragments or that an identifiability threshold exists in a highly fragmented assemblage. If the latter is the case, then below a certain fragment size, specimens become unidentifiable to element (e.g. Marshall and Pilgram 1991; see also Marean and Kim 1998). For Twilight Beach, NISP:MNE is low, indicating low fragmentation intensity, which supports the conclusion that small fragments are rare in the assemblage and the distributions of fragment size are not related to identifiability. Further, the distribution for radii is bimodal; the mode at the lower end represents proximal epiphyses, which comprise about one-third of the sample of radii. This pattern suggests that

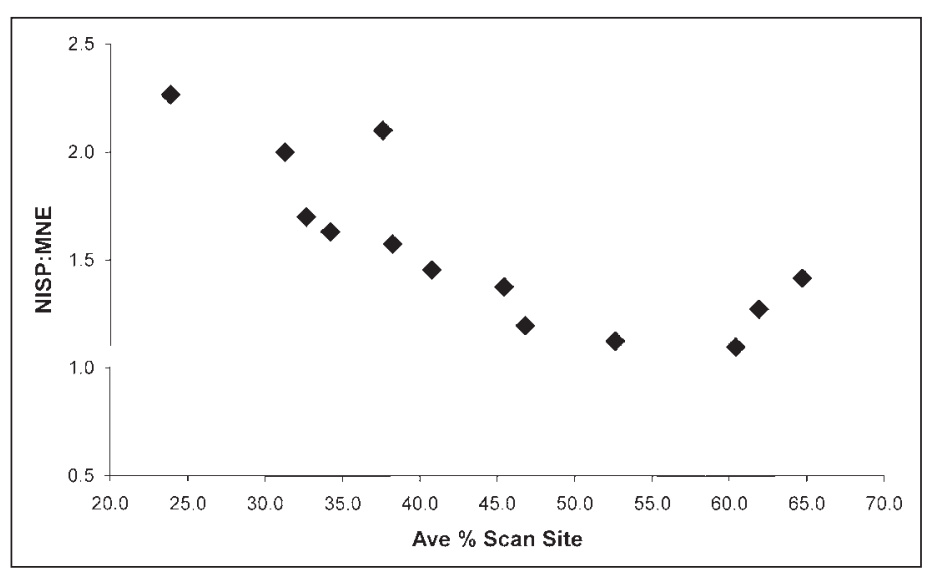

Figure 6. Scatter plot between average percent scan site and NISP:MNE.

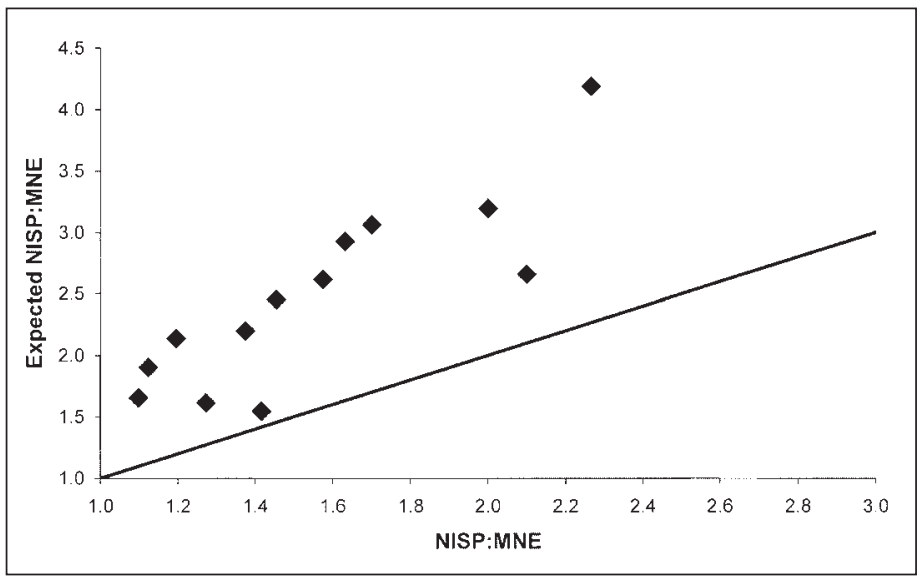

Figure 7. Comparison of expected NISP:MNE as measured by average percent scan site and the actual NISP:MNE values. The line represents the expected values if scan- site data accurately estimate the NISP:MNE value. 
Table 3. Modern size range elements and the average fragment size of the Twilight Beach seal remains.

\begin{tabular}{llll}
\hline Element & Size range $(\mathrm{mm})$ & Average fragment size $(\mathrm{mm})$ & Average \% scan site \\
\hline Humerus & $67-150+$ & 64.6 & $46.8 \%$ \\
Radius & $71-152$ & 47.7 & $34.2 \%$ \\
Femur & $38-95$ & 43.4 & $45.5 \%$ \\
Ulna & na & 82.9 & $60.4 \%$ \\
\hline
\end{tabular}

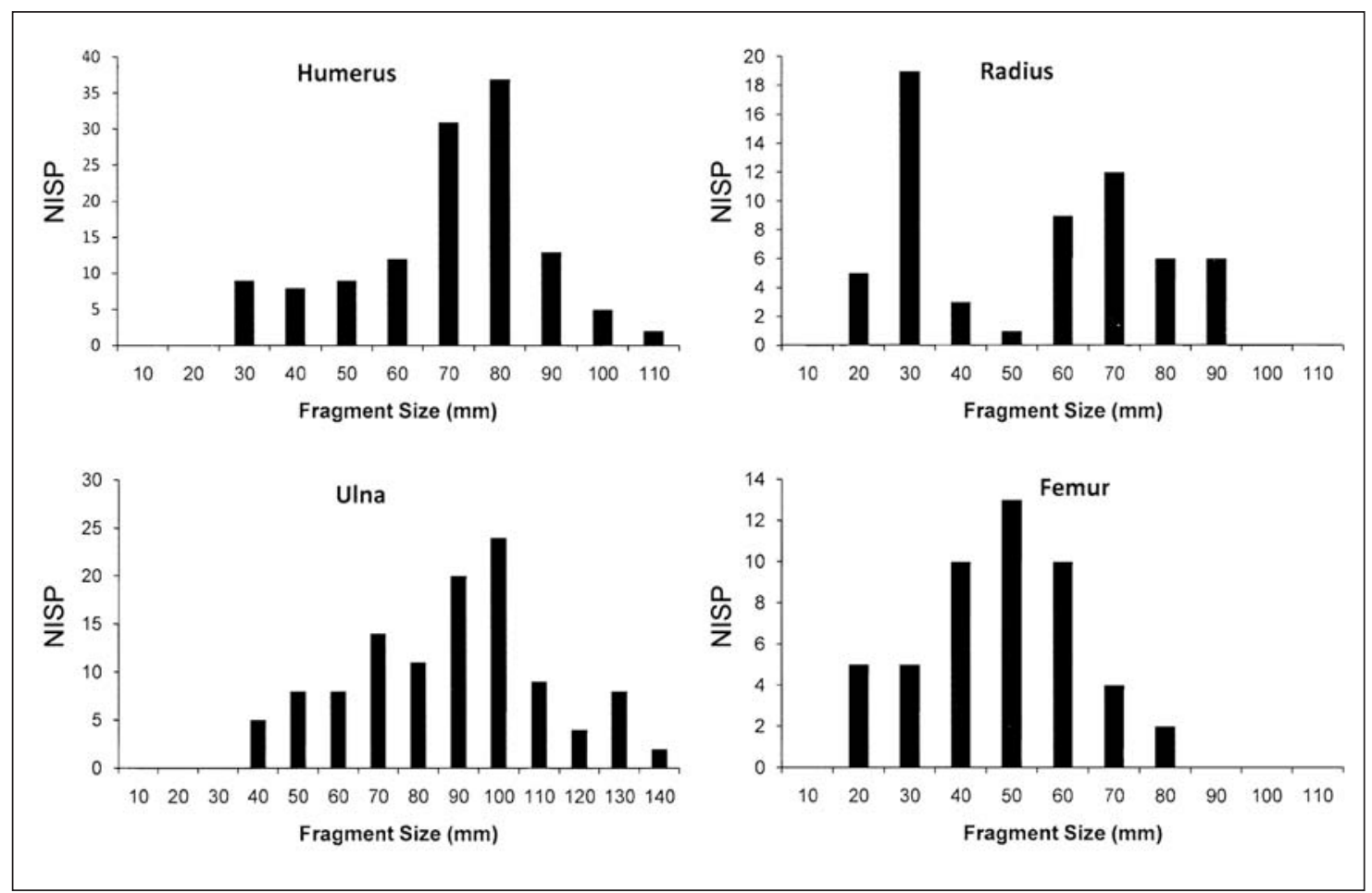

Figure 8. Frequency graphs of fragment size for several long-bone elements.

even when small portions - in this case unfused epiphyses - are present, they are identifiable.

Average percent scan site is theoretically an approximation of fragment size; in order to evaluate this relationship empirically, fragment-size measurements are compared with the scansite data (Table 3). The size range for each skeletal element varies considerably because fur seals grow until they are six to 10 years old, depending on the sex. Thus, the lower end of the range represents pups, while the upper end is adult males. As a result, it is not possible to convert the fragment-size data into the proportion of the element that is represented. However, at ordinal scale, the two measures appear to be comparable. The element with the largest average fragment size is the ulna and it is also the element with the greatest average percent scan site represented. A sample of fragment-size data across a larger range of elements is needed to fully understand how well percent scan site reflects fragment size for fur seals. While determining how these measurements of fragmentation relate to one another is tentative for this sample, they are very useful as ordinal scale measures when making comparisons across assemblages.

\section{Weathering}

Weathering is a taphonomic process that occurs when bone is left exposed on the surface. The bone often becomes bleached and cracked. Behrensmeyer (1978) developed several weathering 
stages that focused mainly on the physical breakdown of bone in the form of cracking. For this analysis, however, we recorded only the presence or absence of cracking or bleaching. Weathering was the most common taphonomic process represented in the seal assemblage, with more than 13 percent of the bones showing signs (Table 1). Most specimens were not highly weathered (Figure 9), and probably fall into Stage 1 of Behrensmeyer's (1978) weathering stages. Weathered bones should be expected, given that the faunal material was eroding out of the dunes. In fact, the provenance of the weathered bone is telling; a significant percentage comes from the surface contexts (Table 4). Thus, most of the weathering probably occurred recently. The low weathering percentage for bones from non-surface contexts supports Taylor's

Table 4. Number of weathered specimens and the percentage of those weathered specimens found in surface contexts.

\begin{tabular}{lll}
\hline Element & $\begin{array}{l}\text { \# weathered } \\
\text { specimens }\end{array}$ & $\begin{array}{l}\text { \% specimens surface } \\
\text { recovered }\end{array}$ \\
\hline Cranium & 5 & 60.0 \\
Mandible & 15 & 53.3 \\
Vertebrae & 7 & 100.0 \\
Ribs & 426 & 47.7 \\
Scapula & 6 & 100.0 \\
Humerus & 14 & 92.9 \\
Radius & 8 & 75.0 \\
Ulna & 12 & 66.7 \\
Innominate & 1 & 100.0 \\
Femur & 4 & 100.0 \\
Tibia & 5 & 100.0 \\
Metapodial & 3 & 100.0 \\
Phalange & 1 & 0.0 \\
\hline
\end{tabular}

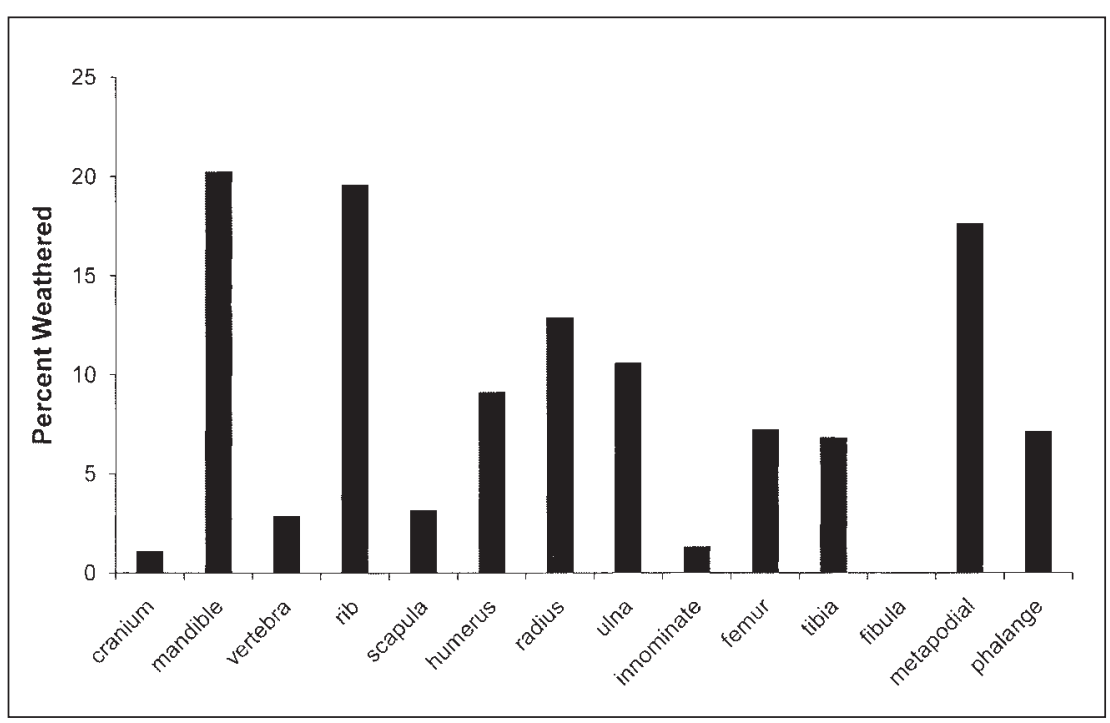

Figure 9. Percentage of weathered specimens across elements. 
(1982:199) interpretation that the site was formed as a result of rapid deposition. For purposes of this general taphonomic study, the fact that the weathering is light and only occurs on a small proportion of the assemblage indicates it was not an important destructive agent that would have removed low-density skeletal parts in the Twilight Beach fauna's accumulation history.

\section{Animal damage}

Animal damage includes rodent gnawing and carnivore gnawing. Only a small fraction of the seal bones exhibits any evidence of rodent gnawing (Table 1). In mild contrast, nine percent of the seal assemblage is carnivore gnawed. The elements displaying the most damage are the long bones, with about 50 percent or more of these elements exhibiting evidence of carnivore gnawing (Figure 10). Carnivore damage tends to occur on the ends of long bones because the proximal and distal ends contain more fat in cancellous bone, making them more attractive than shafts to carnivores (Marean and Spencer 1991; Marean and Kim 1998; Pickering et al. 2003). In addition, these ends tend to be less dense than shafts and thus are likely to be sensitive to any type of taphonomic agent. As a result, carnivore gnawing (and other processes) can differentially affect the sample of long-bone ends in faunal assemblages (Klein 1975; Marean and Kim 1998; Pickering et al. 2003).

To examine whether or not carnivore gnawing played a role in the attrition of longbone ends, we analyse the proportional abundance of carnivore gnaw marks relative to the distribution of density between proximal and distal ends (as in Binford 1981). It is expected that the 'spongier' ends (Bunn 1986) - or lower-density ends (Lyman 1984) - are more susceptible to damage by carnivores. In addition, cancellous bone contains more grease, which may make epiphyseal ends more attractive to carnivores. As a result, we assume that dogs preferentially gnawed on low-density ends and thus those portions should exhibit a higher proportion of gnaw marks. Table 5 shows the density values for proximal and distal ends of seal long bones. As expected, the proximal ends of tibiae and the distal ends of radii, ulnae and metapodials are more frequently gnawed than the denser ends (Table 5). However, for humeri and femora, proximal and distal ends are evenly gnawed. In fact, of the long bones examined, more than 50 percent of the specimens for these two elements are carnivore-gnawed at both ends, supporting the even pattern of gnaw marks across these elements (Table 6). Femora still follow the less dense/more gnawed pattern, but the difference between the two ends is minimal. Even though the difference in density between proximal and distal ends of humeri is one of the largest for long bones in seals, the presence of gnaw marks in the Twilight Beach sample is the same for both ends. This indicates that in those cases in which carnivores gnawed on femora and humeri (roughly 50 percent), they showed no preference about which end.

To determine whether gnawing preference affects the presence of ends in the assemblage, we consider whether or not ends are under-represented compared with shafts, using a ratio of shafts to ends for long bones in the Twilight Beach assemblage (Table 7). MNEs for shafts and ends are tabulated using scan-site counts across portions. If ends and shafts are equally represented, then the ratio should be 0.5 (i.e. one shaft per two ends). As Table 7 shows, only metapodials have an even representation of shafts to ends. Radii and ulnae exhibit about three times as many shafts as expected, given the number of proximal and distal ends, while humeri, femora and tibiae have five to six times as many shafts as ends. Since skeletal-element fragmentation related to marrow extraction and other processes is minimal (see above), these data suggest a substantial proportion of proximal and distal long-bone ends have been lost to carnivore gnawing. The ends of humeri, femora and tibiae are larger and likely contain more fat than those of radii, ulnae and metapodials, making them more attractive to carnivores. 
The distribution of carnivore gnawing across elements at Twilight Beach is not straightforward and highlights the need not to treat any particular taphonomic process simplistically. It is commonly stated that expectations regarding carnivore gnawing effects on long-bone ends are uniform across faunas in a 'law-like' (immanent) manner (Marean and Cleghorn 2003; Pickering

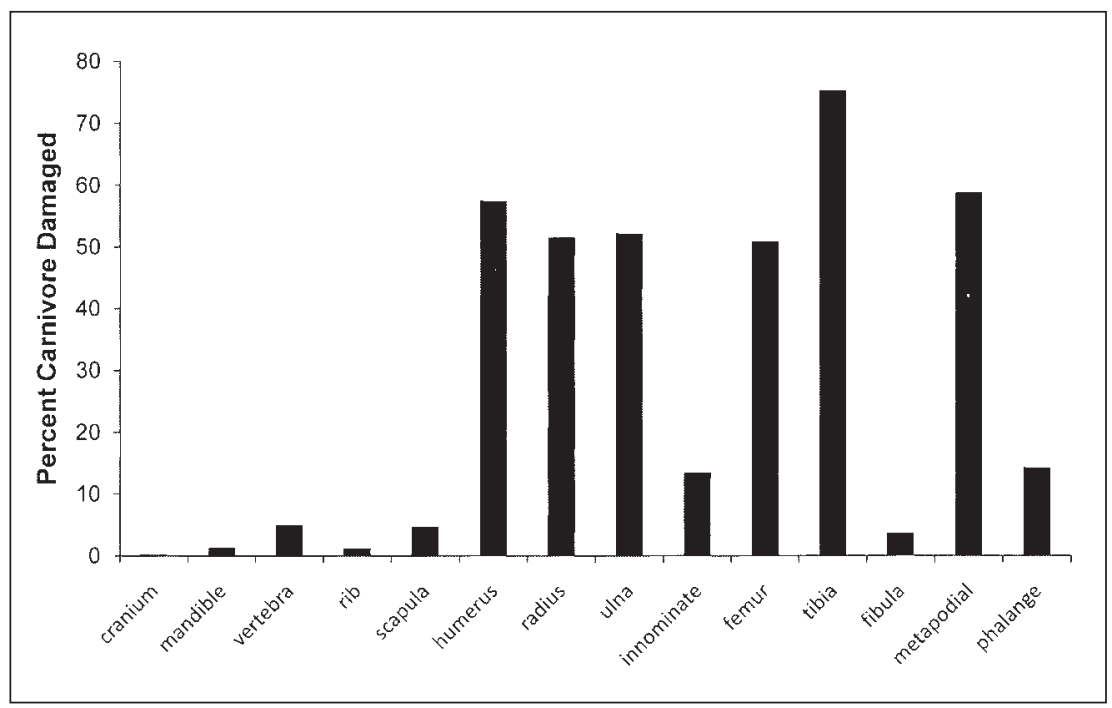

Figure 10. Percentage of carnivore- damaged specimens across elements.

Table 5. Distribution of carnivore gnaw marks across proximal and distal ends of the most commonly damaged limb elements, and the bone mineral densities for the proximal and distal ends of those elements (Chambers 1992). The underlined values are the ends that are less gnawed and those with higher bone densities.

\begin{tabular}{llllll}
\hline \multirow{2}{*}{ Element } & \multirow{2}{*}{$\begin{array}{l}\text { No. of gnawed } \\
\text { Specimens }\end{array}$} & Percentage & \multicolumn{3}{c}{ Density } \\
\cline { 3 - 6 } & Proximal & Distal & Proximal & Distal \\
\hline Humerus & 88 & 77.3 & 77.3 & 0.43 & 0.60 \\
Radius & 32 & 40.6 & 87.5 & 0.63 & 0.45 \\
Ulna & 59 & 25.4 & 47.5 & 0.44 & 0.35 \\
Femur & 28 & 78.6 & 75.0 & 0.50 & 0.57 \\
Tibia & 55 & 85.5 & 56.4 & 0.39 & 0.48 \\
Metapodial & 10 & 40.0 & 80.0 & no data & no data \\
\hline
\end{tabular}

Table 6. Percentage of carnivore-damaged long bones gnawed at both ends.

\begin{tabular}{ll}
\hline Element & \% Carnivore gnaw marks at both ends \\
\hline Humerus & 54.5 \\
Radius & 28.1 \\
Ulna & 15.3 \\
Femur & 53.6 \\
Tibia & 41.8 \\
Metapodial & 20.0 \\
\hline
\end{tabular}

Table 7. Proportion of long-bone shafts to proximal and distal ends.

\begin{tabular}{ll}
\hline Element & Shaft:Ends \\
\hline Humerus & 2.8 \\
Radius & 1.7 \\
Ulna & 1.5 \\
Femur & 3.1 \\
Tibia & 2.6 \\
Metapodial & 0.6 \\
\hline
\end{tabular}


et al. 2003). Our study accentuates that taphonomic histories related to multiple processes need to be examined on an assemblage by assemblage basis, and the effects of any particular process are expected to be diverse across faunas, related to distinctive contingencies relevant to particular taphonomic histories (Lyman 1994a; Stiner 1994).

\section{Cut marks}

Cut marks have been an important part of taphonomic studies, particularly for research examining the question of hominid subsistence practices (e.g. Bunn 1981; Bunn and Kroll 1986; Lyman 1987). Research on cut marks has focused on identifying cut marks as distinguished from natural taphonomic effects (e.g. Olsen and Shipman 1988), documenting the distribution of cut marks across a carcass to reconstruct butchering patterns (e.g. Lupo and O'Connell 2002; Lyman 2005), and using the number or density of cut marks to indicate intensity of butchering (e.g. Abe et al. 2002; Egeland 2003). For example, in Taylor's (1982) original analysis of the Twilight Beach seals, he documented where cut marks tended to occur to reconstruct the butchery process. In other research, a high frequency of cut marks at different locations on the skeleton has been used to suggest that foragers were processing carcasses more intensively. However, recent experimental work has shown that the number of cut marks left on a bone is accidental and often does not correlate with the number of cutting strokes, nor butchering intensity (Egeland 2003). Thus, cut marks may best be used to indicate that butchering has occurred and to determine which elements were removed, or had meat removed from them.

For the Twilight Beach fur-seal assemblage, cut marks were found on fewer than five percent of the specimens. Most elements, except metapodials, exhibit some cut marks. Mandibles and humeri have the highest proportions of cut marks, followed by femora and phalanges (Figure 11). Since cut marks are left when muscle or elements are being removed from a carcass, they contribute to understanding carcass exploitation at the Twilight Beach site. For example, the cut marks on humeri are found mainly on the proximal end of the element, on muscle attachments such as the greater tuberosity, the lesser tuberosity and the deltoid ridge, suggesting either that meat was being removed from the shoulder area, or that humeri were being detached from scapulae. In contrast, lower forelimb elements have fewer cut marks, suggesting these portions were less commonly butchered. However, caution must be taken when using these data because sample sizes are relatively small. For most elements, the number of specimens with cut marks is fewer than 10. Thus, any patterns in cut-mark location may be products of sampling error, which may result in spurious conclusions. In addition, given the loss of long-bone ends to carnivore damage, cut marks that potentially occurred on these ends as a result of element disarticulation are missing.

\section{Burning}

Burning was recorded only as present or absent for the Twilight Beach seal assemblage; no attempt was made to record the degree or extent of burning. Only 4.2 percent of the fur-seal remains exhibit signs of burning. Most of the burning is found on the lower limbs, particularly the phalanges and metapodials (Figure 12). It is possible these elements were burned as anatomical units (that is, as whole flippers, rather than individual elements). Burned bone can be an indication of cooking; however, bone can also be burned incidentally as a result of other cultural or natural processes (Stiner et al. 2005). There are few ethnographic descriptions of how seals were cooked, and each seems to describe a different method (Anderson 1994; Smith 1996). Seal carcasses could have been butchered and cooked in underground ovens, or the meat could have been preserved in fat and stored in kelp bags, or they could have been smoked. So 


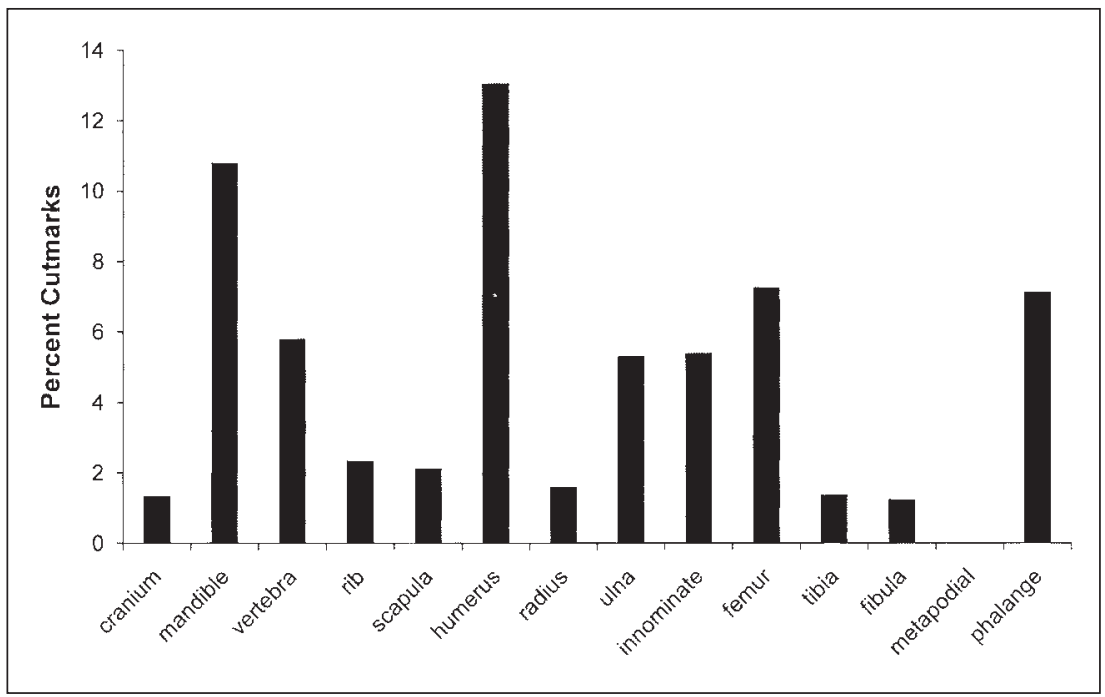

Figure 11. Percentage of specimens with cut marks across elements.

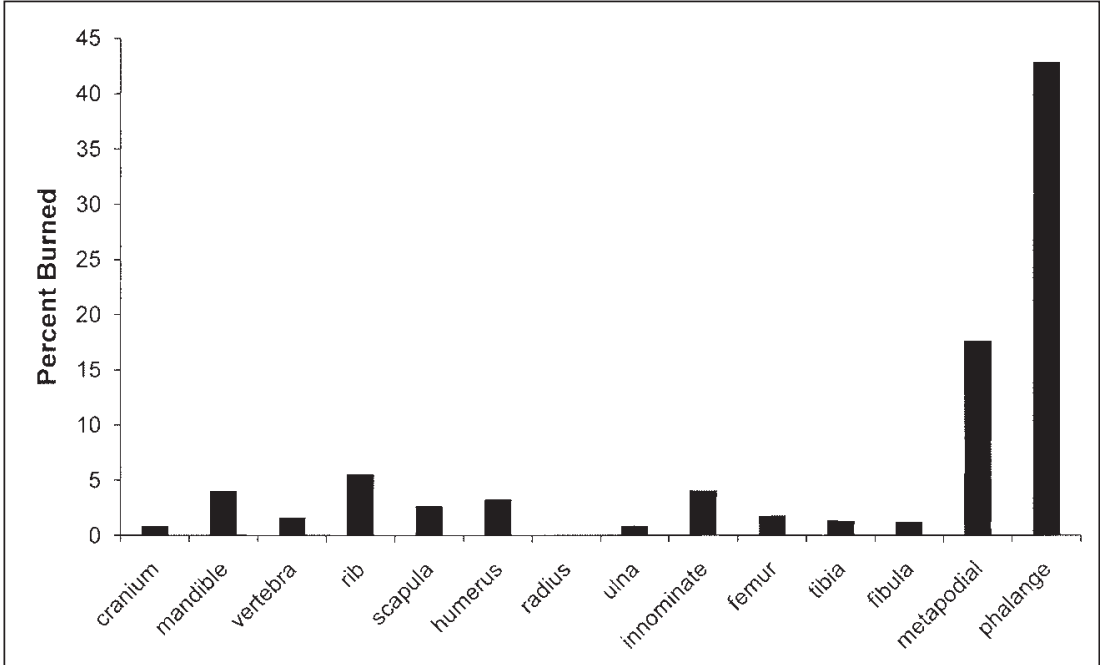

Figure 12. Percentage of burned specimens across elements.

it is unclear what to expect for cooked bone in New Zealand sites, particularly from early sites, where processing and cooking methods may have differed from those described historically. What we do know is there are no cut marks on metapodials and few on phalanges, so it does not appear that flippers were being disarticulated during butchery. There is a significant amount of carnivore damage on metapodials but not on phalanges, so dogs may have had differential access to them, or a preference for one over the other. However, like the cut-mark data, the frequency of burning is so low that caution must be taken when trying to extract patterns from the data and when relating those patterns to past human actions.

\section{Summary}

In general, the taphonomic history of the Twilight Beach fauna suggests that several processes had minimal effects on frequencies of skeletal parts represented. Low-density skeletal parts are as likely to be preserved as high-density ones, despite the carnivore gnawing on a small portion of the seal remains. Carnivore damage on long bones, however, indicates that in many cases ends were destroyed by gnawing, and this pattern tended to affect long bones with larger epiphyseal 
Table 8. Values for seal food utility (FUI), skeletal element representation (\%MAU) and percent carnivore damage for each element. Food utility data (FUI) from Savelle et al. (1996).

\begin{tabular}{llll}
\hline Element & FUI & \%MAU & \% Carnivore damage \\
\hline Cranium/mandible & 27.4 & 38.21 & 0.7 \\
Cervical & 35.9 & 10.73 & 7.6 \\
Thoracic & 24.9 & 3.66 & 4.2 \\
Lumbar & 32.9 & 0.97 & 9.1 \\
Ribs & 100.0 & 41.95 & 2.2 \\
Scapula & 19.8 & 68.29 & 7.1 \\
Humerus & 10.7 & 100.00 & 42.2 \\
Radius/ulna & 4.8 & 84.55 & 18.5 \\
Innominate & 44.5 & 30.08 & 12 \\
Femur & 4.5 & 32.52 & 17.9 \\
Tibia/fibula & 16.5 & 50.41 & 29.3 \\
Flipper & 5.0 & 1.63 & 37.5 \\
\hline
\end{tabular}

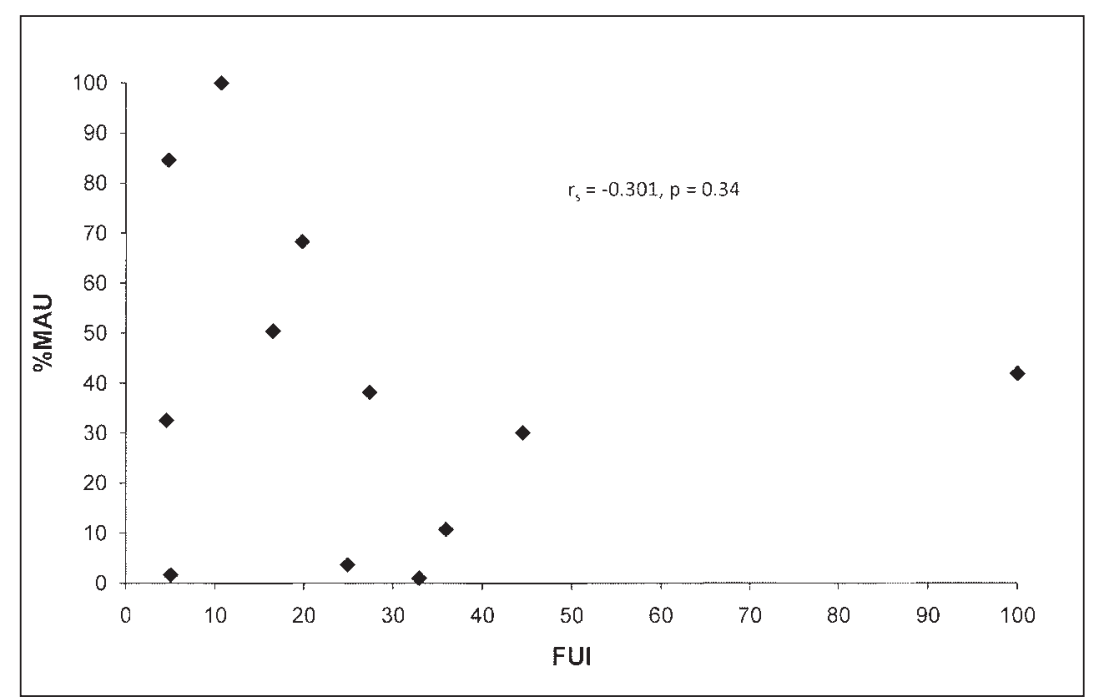

Figure 13. Scatter plot of the values for seal food utility (FUI) and skeletal element representation (\%MAU) for each element.

ends. Carnivore gnawing, though one of the relatively important processes in the Twilight Beach fauna's taphonomic history, did not render long bones unidentifiable and thus had a minimal impact on skeletal part frequencies overall. Along similar lines, evidence of light weathering occurs on parts of the assemblage, but this indicates remains were rapidly buried, which is likely to have enhanced preservation. Burning and butchery are apparent in the assemblage, but probably simply reflect that the assemblage was cultural. However, the occurrence of either process is relatively low, thus study of their effects is limited in terms of detailed analysis of human behaviour. 


\section{Implications for subsistence and semographic interpretations}

The ultimate goals of studying the Twilight Beach seal assemblage are to understand early sealcarcass exploitation and to determine the demographic profile of harvested seals. This taphonomic analysis has an impact on our ability to use the assemblage to address these questions.

\section{Carcass exploitation}

Foraging theory has been very useful in understanding the human decision-making process regarding carcass exploitation (e.g. O’Connell et al. 1988; Bartram 1993; Zeanah 2000; Lupo 2001; Cannon 2003). If foraging efficiency declined as a result of resource depression, the pattern of carcass exploitation would be expected to change. In particular, the kinds of skeletal elements found at archaeological sites are predicted to vary depending on their nutritional returns or 'utility' (Binford 1981; Metcalfe and Jones 1989). Elements transported to sites are affected by the transport costs involved (Cannon 2003; Nagaoka 2006). If transport distance and thus transport costs increase, then the mean utility or net returns of the skeletal elements transported should also increase. In other words, foragers will focus on transporting higher-utility elements when transport costs increase. However, in settings in which people exploited local resources and transport costs are low, a broader range of elements should have been taken back to the site, with declining foraging efficiency. That is, with low transport costs, it is advantageous to intensify carcass exploitation, with a decline in resource availability.

Analysis of carcass exploitation related to foraging efficiency relies on skeletal-part representation data. Thus, it is important to evaluate the taphonomic history of an assemblage to understand whether the patterns in skeletal-part frequencies are due to past butchery and transport practices or to taphonomic processes. For example, to examine whether carcass parts were being transported back to the site based on their nutritional value, we can compare the relative skeletal abundance (\%MAU) of each element with its utility (FUI, Savelle et al. 1996). Analysis of the Twilight Beach fur-seal data shows that skeletal-element abundance is not correlated with food utility at an ordinal level $\left(r_{s}=-0.301, p=0.34\right.$; without outlier $r_{s}=-0.409, p$ $=0.21$ ). Thus, it appears that instead of transporting elements preferentially, based on nutritional returns, humans transported most parts of seal carcasses to the site (Figure 13, Table 8). Overall, the taphonomic history appears to have been minimally important in forming the assemblage. The bone-density analysis suggests the distribution of elements is not due to differential attrition of low-density parts. In addition, there is little weathering across the assemblage and the intensity of fragmentation is low. However, carnivore damage could have played a significant role in the preservation of skeletal elements.

To determine whether carnivore gnawing affected element abundances in the Twilight Beach seal assemblage, we compared carnivore damage with food utility across elements. There is a significant negative correlation between the percent of carnivore damage and FUI (Figure 14, $\mathrm{r}_{\mathrm{s}}=-0.643, \mathrm{p}=0.24$; Table 8 ), suggesting that dogs (Canis familiaris) primarily had access to and were gnawing on relatively low-utility skeletal parts. Thus, in an analysis of carcass exploitation, low-utility elements may be under-represented, due to carnivore damage. However, our analysis of carnivore gnawing suggests that when dogs had access to long bones, they tended to destroy ends, and long bones were not sufficiently damaged to render them unidentifiable and analytically absent from the fauna. The low frequency of carnivore damage across the assemblage, the fact that most destructive damage occurred in long-bone ends, and the fact that end-damage did not render elements unidentifiable indicate the effect of carnivore damage on skeletal-part frequencies is limited. 
Perhaps the most important taphonomic variable, fragmentation, relates to multiple processes. However, given that non-cultural processes appear to have only mildly affected the fauna during its taphonomic history, fragmentation patterns are likely to reflect carcass exploitation by humans for use of within-bone nutrients (see Nagaoka 2005b, 2006). As a result, the intensity and extent of fragmentation can be used to examine whether the use of within-bone nutrients intensified or declined through time, which can be related to a broader study of carcass-part transport and exploitation related to foraging efficiency.

\section{Mortality analysis}

Previous research on the Twilight Beach seal fauna suggests people exploited seals from a rookery near the site (Smith 1985). Given fur seals no longer breed in the region, identifying prehistoric rookeries is important for understanding changes in seal distribution, as well as providing information to conservation biologists about possibilities for expanding modern seal breeding grounds. Morphometric data on prehistoric fur-seal remains are important for identifying the population structure of exploited seals. In particular, the presence of pre-weaned pups and the paucity of sub-adult males can indicate that rookeries, rather than haul outs, were exploited, as indicated by Smith (1985). Pups do not travel far from rookeries early in their lives and subadult males are excluded from adult-male territories.

Two taphonomic problems relate to the abundance of individuals in these two age/sex cohorts at Twilight Beach. First, our taphonomic analysis suggests sub-adult male remains might be under-identified in this assemblage because long-bone ends are preferentially destroyed by carnivores. It is the presence of large, unfused long-bone ends that allows identification of members of this age/sex cohort. However, based on those long bones that are well preserved, large, unfused specimens (sub-adult males) are uncommon, indicating a rookery was exploited (Figure 15).

Second, while the presence of pups can be used to indicate exploitation of rookeries, the larger the sample of pup remains, the more convincing the argument. However, skeletal elements of pups are low in density, and thus are more likely to be destroyed by taphonomic processes (see Symmons 2005; Wolverton 2001, 2006 for similar discussions). Therefore, it is important to examine the taphonomic history of the sample to determine whether pups are rare or

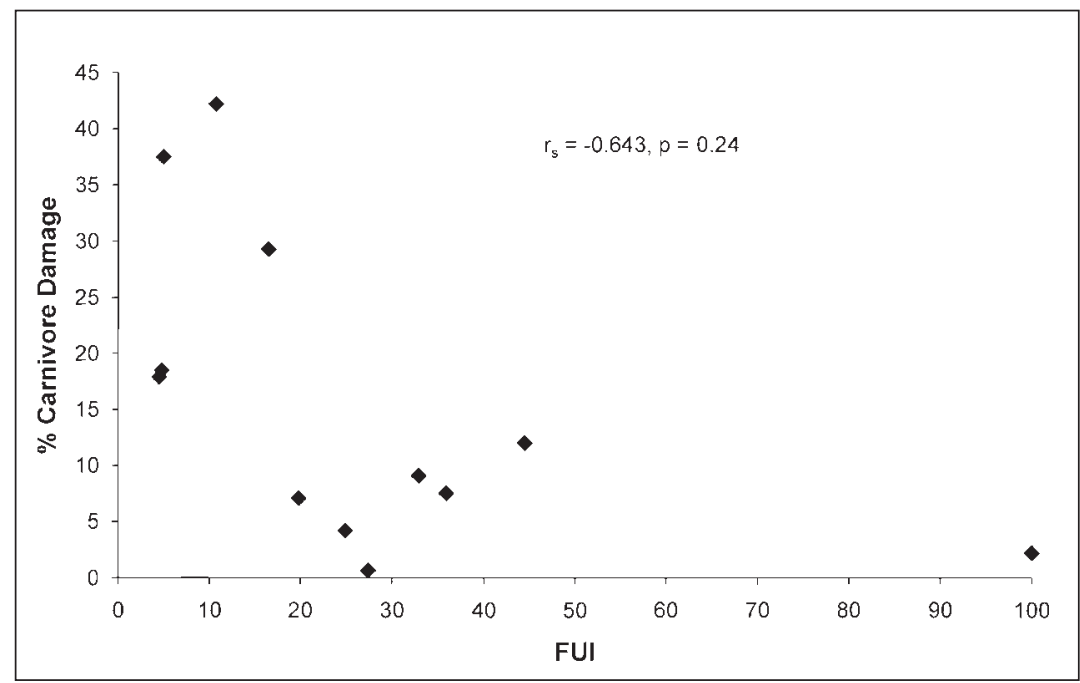

Figure 14. Scatter plot of the rank order of seal food utility and percentage of carnivoredamaged specimens for each element. 


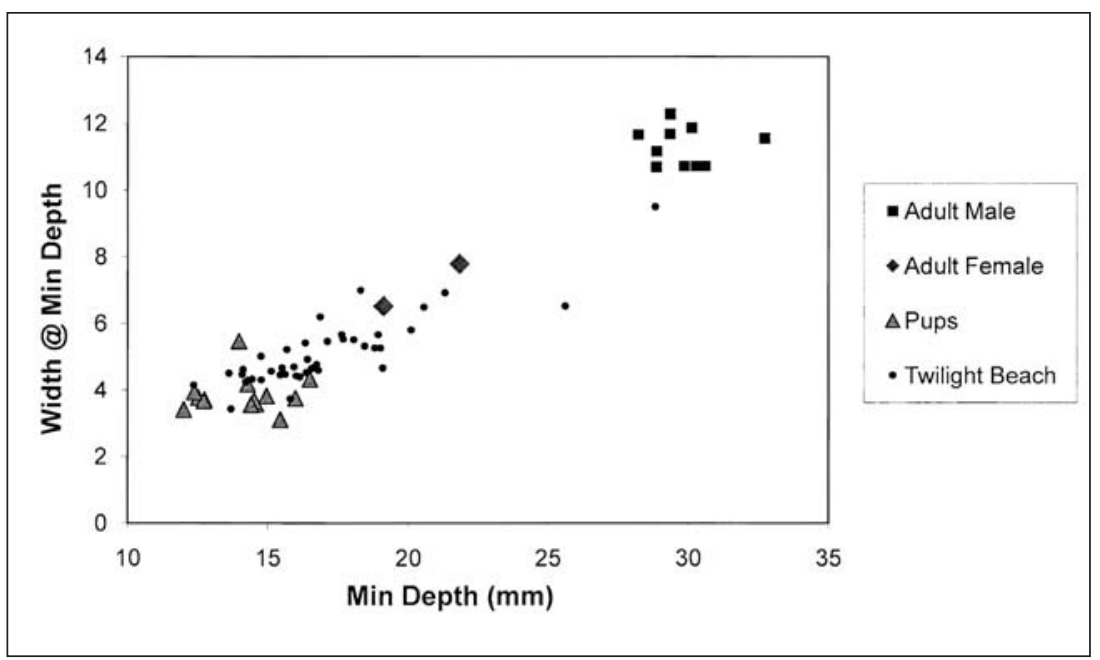

Figure 15. Comparison of modern seal mandible measurements with those from Twilight Beach to illustrate the demographic composition of the seals from the site.

absent because of exploitation patterns or preservation. Our analysis suggests density-mediated destruction of remains and related taphonomic processes did not cause substantial damage to the Twilight Beach fauna. As a result, we suggest the abundance of pup remains is representative of the demographic structure of seal hunting by prehistoric foragers at Twilight Beach.

\section{Conclusions}

Taphonomic analysis is not undertaken in a vacuum, but helps shed light on broader research problems. Nonetheless, there is apparent fission in modern zooarchaeology about the role taphonomic analysis and quantification should play (compare Marean and Kim 1998 with Stiner 1998, and Pickering et al. 2003 with Stiner 2002). Our position is that taphonomic histories vary by assemblage and appropriate quantitative analysis should vary by research problem. Acknowledging a conceptual framework for taphonomy (e.g. Gifford-Gonzalez 1991; Lyman 1994a) that recognises the different roles that immanent and configurational properties play in taphonomic analysis highlights that diversity in taphonomic effects is to be expected. Although it is tempting to treat the effects of particular taphonomic processes, such as the role of carnivore damage in density-mediated attrition, as uniform (e.g. Marean and Cleghorn 2003; Pickering et al. 2004), contingencies of accumulation histories might as easily and uniformly be expected to vary through time and across space. As a result, any particular assemblage must be evaluated on an individual basis for the analytical role it can play in a particular research question. Taphonomic methods should be creative and diverse to account for the myriad permutations and magnitudes that attritional agents can play in taphonomic histories of archaeological faunas.

\section{Acknowledgements}

We thank Michael Taylor for access to data, samples and related materials from Twilight Beach. The Department of Anthropology at the University of Auckland provided laboratory space for analysis and access to the collections. This research was funded by NSF Grant BCS-0408963 and Research Experience for Undergraduate (REU) supplement. 


\section{References}

Abe, Y., W.M. Curtis, J.N. Peter, A. Zelalem and C.E Stone 2002. The analysis of cutmarks on archaeofauna: A review and critique of quantification procedures and a new image-analysis GIS approach. American Antiquity 67:643-663.

Anderson, A.J. (ed) 1994, Traditional Lifeways of the Southern Maori. Dunedin: University of Otago

Bartram, L.E. Jr. 1993. Perspectives on skeletal part profiles and utility curves from eastern Kalahari ethnoarchaeology. In J. Hudson (ed), From Bones to Behavior: Ethnoarchaeological and Experimental Contributions to the Interpretation of Faunal Remains, pp. 115-137. Southern Illinois University, Carbondale: Center for Archaeological Investigations.

Behrensmeyer, A.K. 1978. Taphonomic and ecologic information from bone weathering. Paleobiology 4:150-162.

Binford, L.R. 1981. Bones: Ancient Men and Modern Myths. New York: Academic.

Binford, L.R. 1984. Faunal Remains from Klasies River Mouth. New York: Academic.

Bradshaw, C.J.A., S.D. Lloyd, P. Martin, Z. Qingqing and L.B George 2002. Using artificial neural networks to model the suitability of coastline for breeding by New Zealand fur seals (Arctocephalus forsteri). Ecological Modelling 148:111-131.

Bradshaw, C.J.A., L. Chris and M.T. Caryn 2000. Clustering of colonies in an expanding population of New Zealand fur seals (Arctocephalus forsteri). Journal of Zoology 250:105-112.

Brain, C.K. 1969. The contribution of the Namib Desert Hottentots to an understanding of Australopithecine bone accumulations. Scientific Papers of the Namib Desert Research Station 39:13-22.

Broughton, J.M. 1999. Resource Depression and Intensification during the Late Holocene, San Francisco Bay: Evidence from the Emeryville Shellmound. University of California, Anthropological Records Volume 32.

Bunn, H.T. 1981. Archaeological evidence for meat-eating by Plio-Pleistocene hominids from Koobi Fora and Olduvai Gorge. Nature 291:574-477.

Bunn, H.T. 1986. Patterns of skeletal representation and hominid subsistence activities at Olduvai Gorge, Tanzania, and Koobi Fora, Kenya. Journal of Human Evolution 15:673-690.

Bunn, H.T. and E.M. Kroll 1986. Systematic butchery by Plio-Pleistocene hominds at Olduvai Gorge, Tanzania. Current Anthropology 27:431-452.

Butler, V.L. and C.C. James 1994. The role of bone density in structuring prehistoric salmon bone assemblages. Journal of Archaeological Science 21:413-424.

Cannon, M.D. 2003. A model of central place forager prey choice and an application to faunal remains from the Mimbres Valley, New Mexico. Journal of Anthropological Archaeology 22:1-25.

Chambers, A. 1992. Seal Bone Mineral Density: Its Effect on Specimen Survival in Archaeological Sites. Unpublished BA Honors Thesis, University of Missouri.

Clark, G.R. 1995. The Kuri in Prehistory. Unpublished MA thesis, University of Otago.

Clark, G. 1997a. Osteology of the kuri Maori: The prehistoric dog of New Zealand. Journal of Archaeological Science 24:113-126.

Clark, G.R. 1997b. Maori subsistence change: Zooarchaeological evidence from the prehistoric dog of New Zealand. Asian Perspectives 36:200-219.

Coster, J. 1989. Dates from the dunes: A sequence for the Aupouri Peninsula, Northland New Zealand. New Zealand Journal of Archaeology 11:51-75.

Cruz, I. and E. Dolores 2003. Structural Bone Density of the Lesser Rhea (Pterocnemia pennata) (Aves: Rheidae). Taphonomic and Archaeological Implications. Journal of Archaeological Science 30:37-44.

Darwent, C.M. and R.L. Lyman 2002. Detecting the postburial fragmentation of carpals, tarsals, and phalanges. In W.D. Haglund and M.H. Sorg (eds), Advances in forensic taphonomy: Method, theory and archaeological perspectives, pp. 356-377. Boca Raton: CRC Press. 
Dirrigl, F.J. 2001. Bone Mineral Density of Wild Turkey (Meleagris gallopavo) Skeletal Elements and its Effect on Differential Survivorship. Journal of Archaeological Science 28:817-832.

Egeland, C.P. 2003. Carcass processing intensity and cutmark creation: An experimental approach. Plains Anthropologist 48:39-51.

Fisher, J.W. Jr. 1995. Surface modification of bone. Journal of Archaeological Method and Theory 2:7-68.

Gifford-Gonzalez, D.P. 1991. Bones are not enough: Analogues, knowledge, and interpretive strategies in zooarchaeology. Journal of Anthropological Archaeology 10:215-254.

Gordon, E.A. 1993. Screen size and differential faunal recovery: A Hawaiian example. Journal of Field Archaeology 20:453-460.

Grayson, D.K. 1984. Quantitative Zooarchaeology. New York: Academic.

Guthrie, R.D. 1967. Differential preservation and recovery of Pleistocene large mammal remains in Alaska. Journal of Paleontology 41:243-246.

Hindelang, M. and L.M. Ann 1997. Bone density determination of moose skeletal remains from Isle Royale National Park using digital image enhancement and quantitative computed tomography (QCT). International Journal of Osteoarchaeology 7:193-201.

Ioannidou, E. 2003. Taphonomy of animal bones: Species, sex, age and breed variability of sheep, cattle and pig bone density. Journal of Archaeological Science 30:355-365.

Izeta, A.D. 2005. South American camelid bone structural density: What are we measuring? Comments on data sets, values, their interpretation and application. Journal of Archaeological Science 32:1159-1168.

Klein, R.G. 1975. Paleoanthropological implications of the nonarchaeological bone assemblage from Swartklip I, south-western Cape Province, South Africa. Quaternary Research 5:275-288.

Klein, RG. and K. Cruz-Uribe 1984. The Analysis of Animal Bones from Archaeology Sites. Chicago: University of Chicago Press.

Kreutzer, L.A. 1992. Bison and deer bone mineral densities: Comparisons and implications for the interpretation of archaeological faunas. Journal of Archaeological Science 19:271-294.

Lam, Y.M., C. Xingbin, W.M. Curtis and J.F Carol 1998. Bone density and long bone representation in archaeological faunas: Comparing results from CT and photon densitometry. Journal of Archaeological Science 25:559-570.

Lam, Y.M., C. Xingbin and O.M. Pearson 1999. Intertaxonomic variability in patterns of bone density and the differential representation of bovid, cervid, and equid elements in the archaeological record. American Antiquity 64:343-362.

Lam, Y.M., O.M. Pearson, W.M Curtis and C. Xingbin 2003. Bone density studies in zooarchaeology. Journal of Archaeological Science 30:1701-1708.

Leach, B.F., J.M Davidson and L.M. Horwood 1997. Prehistoric Maori fishermen at Kokohuia, Hokianga Harbour, Northland, New Zealand. Man and Culture in Oceania 13:99-116.

Lupo, K.D. 2001. Archaeological skeletal part profiles an differential transport: An ethnoarchaeological example from Hadza bone assemblages. Journal of Anthropological Archaeology 20:361-378.

Lupo, K.D. and J.F. O'Connell 2002. Cut and tooth mark distributions on large animal bones: ethnoarchaeological data from the Hadza and their implications for current ideas about early human carnivory. Journal of Archaeological Science 29:85-109.

Lyman, R.L. 1984. Bone density and differential survivorship of fossil classes. Journal of Anthropological Archaeology 3:259-299.

Lyman, R.L. 1987. Archaeofaunas and butchery studies: A taphonomic perspective. In M.B. Schiffer (ed), Advances in Archaeological method and theory Vol. 10, pp. 249-337. San Diego: Academic Press.

Lyman, R.L. 1994a. Vertebrate Taphonomy. Cambridge: Cambridge University.

Lyman, R.L. 1994b. Quantitative units and terminology in zooarchaeology. American Antiquity 59:36-71. 
Lyman, R.L. 1994c. Relative abundances of skeletal specimens and taphonomic analysis of vertebrate remains. Palaios 9:288-298.

Lyman, R.L. 2005. Analyzing cut marks: lessons from artiodactyl remains in the northwestern United States. Journal of Archaeological Science 32:1722-1732.

Lyman, R.L. 2008. Quantitative Paleozoology. Cambridge: Cambridge University Press.

Lyman, R.L and M.J. O’Brien 1987. Plow-zone zooarchaeology: Fragmentation and identifiability. Journal of Field Archaeology 14:493-498.

Lyman, R.L., L.E. Houghton and A.L. Chambers 1992. The effect of structural density on marmot skeletal part representation in archaeological sites. Journal of Archaeological Science 19:557-573.

Marean, C.W. 1991. Measuring the post-depositional destruction of bone in archaeological assemblages. Journal of Archaeological Science 18:677-694.

Marean, C.W. and N. Cleghorn 2003. Large mammal skeletal element transport: Applying foraging theory in a complex taphonomic system. Journal of Taphonomy 1:15-42.

Marean, C.W. and S.Y. Kim 1998. Mousterian large-mammal remains from Kobeh Cave. Comments/ Reply. Current Anthropology 39:S79.

Marean, C.W. and L.M. Spencer 1991. Impact of carnivore ravaging on zooarchaeoloigcal measures of element abundance. American Antiquity 56: 645-658.

Marean, C.W., L.M. Spencer, R.J. Blumenschine and S.D. Capaldo 1992. Captive hyaena bone choice and destruction, the Schlepp effect and Olduvai archaeofaunas. Journal of Archaeological Science 19:101-121.

Marshall, F. and T. Pilgram 1991. Meat versus within-bone nutrients: Another look at the meaning of body part representation in archaeological sites. Journal of Archaeological Science 18:149-163.

Metcalfe, D. and K.T. Jones 1988. A reconsideration of animal body-part utility indices. American Antiquity 53:486-504.

Munro, N.D. 2004. Zooarchaeological measures of hunting pressure and occupation intensity in the Natufian. Current Anthropology 45(Supplement):S5-S33.

Munro, N.D. and G. Bar-Oz 2005. Gazelle bone fat processing in the Levantine Epipaleolithic. Journal of Archaeological Science 32:223-239.

Nagaoka, L. 1994. Differential recovery of Pacific Island fish remains: Evidence from the Moturakau Rockshelter, Aitutaki, Cook Islands. Asian Perspectives 33:1-17.

Nagaoka, L. 2005a. Differential recovery of Pacific Island fish remains. Journal of Archaeological Science 32:941-955.

Nagaoka, L. 2005b. Declining foraging efficiency and moa carcass exploitation in southern New Zealand. Journal of Archaeological Science 32:1328-1338.

Nagaoka, L. 2006. Prehistoric seal carcass exploitation at the Shag Mouth site, New Zealand. Journal of Archaeological Science 33:1474-1481.

Nichol, R. 1988. Tipping the Feather Against the Scale: Archaeozoology from the Tail of a Fish. Unpublished PhD thesis, University of Auckland.

Novecosky, B.J. and P.R.W. Popkin 2005. Canidae volume bone mineral density values: An application to sites in western Canada. Journal of Archaeological Science 32:1677-1690.

O'Connell, J.F., K. Hawkes and N.B. Jones 1988. Hadza hunting, butchering, and bone transport and their archaeological implications. Journal of Anthropological Research 44:113-161.

Olsen, S.L. and P. Shipman 1988. Surface modification on bone: Trampling versus butchery. Journal of Archaeological Science 15:535-553.

Outram, A.K. 2001. A new approach to identifying bone marrow and grease exploitation: Why the 'indeterminate' fragments should not be ignored. Journal of Archaeological Science 28:401-410.

Outram, A.K. 2004. Applied models and indices vs. high-resolution, observed data: Detailed fracture and fragmentation analyses for the investigation of skeletal part abundance patterns. Journal of Taphonomy 2:167-184.

Pavao, B. and P.W. Stahl 1999. Structural density assays of leporid skeletal elements with implications 
for taphonomic, actualistic and archaeological research. Journal of Archaeological Science 26:53-66.

Pickering, T.R. and K.J. Carlson 2002. Baboon bone mineral densities: Implications for the taphonomy of primate skeletons in South African cave sites. Journal of Archaeological Science 29:883-896.

Pickering, T.R., C.W. Marean and M. Dominguez-Rodrigo 2003. Importance of limb bone shaft fragments in zooarchaeology: A response to 'On in situ attrition and vertebrate body part profiles' (2002), by M.C. Stiner. Journal of Archaeological Science 30:1469-1482.

Pickering, T.R., M. Dominguez-Rodrigo, C.P. Egeland and C.K. Brain 2004. Beyond leopards: Tooth marks and the contribution of multiple carnivore taxa to the accumulation of the Swartkrans Member 3 fossil assemblage. Journal of Human Evolution 46:595-604.

Savelle, J.M., T.M. Friesen and R.L. Lyman 1996. Derivation and application of an otariid utility index. Journal of Archaeological Science 23:705-712.

Schiffer, M.B. 1987. Formation Processes of the Archaeological Record. Albuquerque: University of New Mexico.

Shaffer, B.S. 1992. Quarter-inch screening: Understanding biases in recovery of vertebrate faunal remains. American Antiquity 57:129-136.

Shaffer, B.S. and J.L.J. Sanchez 1994. Comparison of 1/8'- and 1/4'-mesh recovery of controlled samples of small- to medium-sized mammals. American Antiquity 59:525-530.

Simpson, G.G. 1963. Historical science. In C.C. Albritton (ed), The fabric of geology, pp. 24-48. Reading: Addison-Wesley.

Smith, I.W.G. 1985. Sea Mammal Hunting and Prehistoric Subsistence in New Zealand. Unpublished $\mathrm{PhD}$ thesis, University of Otago.

Smith, I.W.G. 1996, Historical documents, archaeology and 18th century seal hunting in New Zealand. In J.M. Davidson, G. Irwin, B.F. Leach, A. Pawley and D. Brown (eds), Oceanic culture history. Essays in honour of Roger Green, pp. 675-688. New Zealand Journal of Archaeology Special Publication.

Stahl, P.W. 1999. Structural density of domesticated South American camelid Skeletal elements and the archaeological investigation of prehistoric Andean Ch'arki. Journal of Archaeological Science 26:1347-1368.

Stiner, M.C. 1994. Honor Among Thieves: A Zooarchaeological Study of Neanderthal Ecology. Princeton: Princeton University.

Stiner, M.C. 1998. Comment on Marean and Kim, Mousterian large-mammal remains from Kobeh Cave: Behavioral implications. Current Anthropology 39:s98-s103.

Stiner, M.C. 2002. On in-situ attrition and vertebrate body part profiles. Journal of Archaeological Science 29:979-991.

Stiner, M.C. 2005. The Faunas of Hayonim Cave, Israel: A 200,000-Year Record of Paleolithic Diet, Demography and Society. New Haven: Peabody Museum.

Stiner, M.C., S.L. Kuhn, S. Weiner and O. Bar-Yosef 1995. Differential Burning, Recrystallization, and Fragmentation of Archaeological Bone. Journal of Archaeological Science 22:223-237.

Stiner, M. C., O. Bar-Yosef, S.L. Kuhn and S. Weiner 2005. Experiments in fragmentation and diagenesis of bone and shell. In M.C. Stiner (ed), The faunas of Hayonim Cave, Israel: A 200,000-year record of paleolithic diet, demography and society, pp. 39-58. American School of Prehistoric Research, Bulletin 48.

Symmons, R. 2004. Digital photodensitometry: a reliable and accessible method for measuring bone density. Journal of Archaeological Science 31:711-719.

Symmons, R. 2005. New density data for unfused and fused sheep bones, and a preliminary discussion on the modelling of taphonomic bias in archaeofaunal age profiles. Journal of Archaeological Science 32:1691-1698.

Taylor, M. 1982. Bone Refuse from Twilight Beach. Unpublished MA thesis, University of Auckland.

Todd, L.C. and D.J. Rapson 1988. Long bone fragmentation and interpretation of faunal assemblages: Approaches to comparative analysis. Journal of Archaeological Science 15:307-325. 
Wolverton, S. 2001. Caves, ursides and artifacts: a natural-trap hypothesis. Journal of Ethnobiology 21:55-72.

Wolverton, S. 2002. NISP:MNE and \% whole in analysis of prehistoric carcass exploitation. North American Archaeologist 23:85-100.

Wolverton, S. 2006. Natural-trap ursid mortality and the Kurten Response. Journal of Human Evolution 50:540-551.

Zeanah, D.W. 2000. Transport costs, central-place foraging, and hunter-gatherer alpine land-use strategies. In D.B. Madsen and M.D. Metcalf (eds), Intermountain Archaeology, pp. 1-14. Salt Lake City: University of Utah Press. 